\title{
Opieka pielęgniarska nad pacjentką w przebiegu anoreksji z wykorzystaniem ICNP®
}

\section{Nursing care of patient in the course of anorexia with the ICNP ${ }^{\circledR}$ application}

\author{
KAROLINA CIECHANOWSKA ${ }^{1}$, KAROLINA KRAJEWSKA ${ }^{1}$ \\ 1 Studenckie Koło Naukowe Nauk o Zdrowiuํㅜ, Instytut Nauk o Zdrowiu, Państwowej \\ Uczelni Zawodowej we Włocławku
}

DOI: http://dx.doi.org/10.21784/lwP.2020.005

ISSN: 2451-1846

\section{Streszczenie:}

Wstęp. Anoreksja jest chorobą, na którą cierpi coraz więcej osób, dotyka ona znacznie więcej kobiet i dziewczynek niż mężczyzn oraz chłopców. Chorobę w większości przypadków stwierdza się między 14 a 18 rokiem życia. Osoby chorujące na jadłowstręt psychiczny nagle, nadmiernie rozpoczynają odchudzanie poprzez spożywanie posiłków w niewielkich porcjach o niskiej kaloryczności. Poza nadmierną utratą masy ciała może dojść do niebezpiecznych zaburzeń hormonalnych w organizmie. Poprzez prowadzenie działań mających na celu kreowanie prawidłowego zdrowia psychospołecznego możliwe jest uniknięcie wzrostu zachorowań na anoreksję.

Cel pracy. Celem pracy jest zastosowanie odpowiednich działań pielęgniarskich wobec pacjentki $\mathrm{z}$ anoreksją, przebywającą $\mathrm{w}$ oddziale psychiatrycznym.

Prezentacja przypadku. Pacjentka, lat 20, przebywająca w oddziale psychiatrycznym, uskarża się na odczuwanie silnego lęku spowodowanego obawą przed zwiększeniem masy ciała. Unika obserwowania siebie 
w lustrze. Poprzez długotrwałe zażywanie środków przeczyszczających doszło do znacznego odwodnienia organizmu. Chora wymaga edukacji dotyczącej choroby oraz pomocy w czynnościach samoopielęgnacyjnych. Według przeprowadzonego wywiadu pacjentkę pierwszy raz dotknęły tego typu objawy.

Wnioski. Całościowa opieka zapewniona ze strony personelu medycznego znacznie poprawiła samopoczucie pacjentki, jednak wszystkie działania należy kontynuować, by pacjentka mogła w pełni wyzdrowieć.

Słowa kluczowe: anoreksja, proces pielęgnowania, ICNP®

\begin{abstract}
:
Introduction. Anorexia is a disease that affects more and more people, it ffects many more women and girls than men and boys. In most cases, the disease is diagnosed between 14 and 18 years of age. People with anorexia nervosa suddenly and excessively start losing weight by eating meals in mall, low-calorie portions. In addition to excessive weight loss, there may be dangerous hormonal disorders in the body. By conducting activities aimed at creating proper psychosocial health, it is possible to avoid an increase in the incidence of anorexia.
\end{abstract}

Aim of the study. The purpose of the work is to apply appropriate nursing activities to a patient with anorexia in a psychiatric ward.

Case study. A 20-year-old patient in a psychiatric ward complains of feeling strong anxiety due to fear of weight gain. He avoids watching himself in the mirror. Significant dehydration of the body occurred through prolonged use of laxatives. The patient requires education regarding the disease and help in self-care activities. According to the interview, the patient was affected by this type of symptoms for the first time.

Conclusions. The comprehensive care provided by medical staff has significantly improved the patient's well-being, but all activities should be continued so that the patient can recover fully.

Keywords: anorexia, nursing process, ICNP® 


\section{Wstęp}

Według tłumaczenia $\mathrm{z}$ języka greckiego wyraz anoreksja oznacza brak apetytu albo odczuwanie obrzydzenia do pokarmu. Zdaniem Arthura H. Crisp'a najgorszym faktem w anoreksji jest strach przed przyjęciem posiłku, pomimo odczuwania głodu. Jadłowstręt psychiczny według klasyfikacji ICD-10 nosi miano anorexia nervosa [1]. Problemy $\mathrm{z}$ odżywianiem mają negatywne skutki, przypisuje im się jeden $\mathrm{z}$ najwyższych wskaźników śmiertelności pośród innych chorób psychicznych. Z roku na rok wzrasta liczba osób cierpiących z powodu anoreksji, w związku tym niebezpieczeństwo śmierci także wzrasta. Wskaźnik DALY (disability adjusted life-years) dotyczący nieprawidłowości w odżywianiu, na świecie wynosi około 30 na sto tysięcy populacji. Natomiast według statystyk dla Europy Zachodniej ten wskaźnik wynosi powyżej 70 na sto tysięcy osób. Szacuje się, że w Polsce według DALY na problemy z odżywianiem cierpi około 26 na sto tysięcy ludzi [2]. Anoreksja występuje około 10 razy częściej u kobiet niż u płci przeciwnej, zwykle u osób młodych w przedziale wiekowym między 14 a 18 r.ż.

Anoreksję można stwierdzić na podstawie obserwacji danej osoby. Do jej charakterystycznych cech należą przede wszystkim:

- nagłe, nadmierne odchudzanie,

- spożywanie małej ilości posiłków i brak apetytu,

- ograniczenie produktów wysokokalorycznych,

- dalsze odchudzanie, pomimo spadku kilogramów,

- ubieranie bardzo przylegających ubrań lub za dużych,

- unikanie rozmów o swoich uczuciach [1].

Okazuje się, że im wcześniej wykryje się anoreksję, tym szybciej zatrzymamy przebieg choroby wraz $\mathrm{z}$ jej niezwykle niebezpiecznymi skutkami dla organizmu. Spośród wszystkich stwierdzonych przypadków anoreksji lub bulimii u około $30 \%$ 
cierpiących $\mathrm{z}$ ich powodu stwierdza się dodatkowe choroby przewlekłe [2]. U kobiet najczęściej dochodzi do zaniku miesiączki, natomiast

u mężczyzn do zmniejszenia się libido. Zarówno u kobiet, jak i u mężczyzn mogą wystąpić niepoprawne wartości hormonów tarczycy, hormonu wzrostu oraz insuliny. Poza nieprawidłowymi wartościami stężenia hormonów obserwuje się także m. in.: niższą temperaturę ciała, zawroty głowy, zaparcia, wzdęcia, niedokrwistość, wypadanie włosów, omdlenia, niedokrwistość, zaburzenia rytmu serca[3].

Poprzez kreowanie prawidłowego postrzegania swojej osoby możliwe jest zachowanie zdrowia psychospołecznego. Często jednak nie jest to możliwe, ponieważ człowiek $\mathrm{w}$ niepoprawny sposób postrzega siebie w społeczeństwie oraz nieumiejętnie ocenia swoje wartości, co w późniejszym czasie może skutkować zaburzeniem psychicznym, dotyczy to także anoreksji [4]. Z tego właśnie powodu bardzo ważne jest, by pielęgniarka posiadała odpowiednie kwalifikacje i kompetencje. Dzięki realizacji przez nią świadczeń, takich jak.: rozumienie warunków i potrzeb zdrowotnych, dostrzeżenie problemów pielęgnacyjnych, udzielanie opieki pielęgniarskiej czy wykonywanie zleceń lekarskich możliwa jest poprawa jakości życia pacjentów cierpiących z powodu anoreksji oraz przyczynianie się do pełnego powrotu do zdrowia [5].

\section{Cel}

Celem pracy jest utworzenie opieki pielęgniarskiej nad pacjentką cierpiącą na anoreksję za pomocą zastosowania odpowiednich interwencji i diagnoz pielęgniarskich. W poniższym proponowanym planie opieki oparto się na standardowym modelu procesu pielęgnowania, który został uzupełniony o Międzynarodową Klasyfikację Praktyki Pielęgniarskiej ICNP®. 



\section{Materiał i metody}

W pracy zastosowano metodę indywidualnego przypadku. Techniki zbierania danych wykorzystane $\mathrm{w}$ pracy to: obserwacja chorego, wywiad bezpośredni, analiza dokumentacji medycznej (historii choroby, wyników badań, karty gorączkowej, karty indywidualnej opieki pielęgniarskiej), pomiar podstawowych parametrów życiowych (tętno, ciśnienie tętnicze krwi, częstość oddechów, temperatura ciała). Pacjentka wyraziła zgodę na badanie, które przeprowadzono w styczniu 2020r. Bazując na zebranych informacjach postawiono poniżej określone diagnozy pielęgniarskie oraz przygotowano indywidualny plan opieki pielęgniarskiej z zastosowaniem klasyfikacji ICNP®.

\section{Prezentacja przypadku}

Pacjentka lat 20, urodzona w Toruniu. Mieszka z mamą i tatą. Tata pracuje za granicą od 10-ciu lat. W 2015r. przyjęta była na oddział psychiatryczny z powodu niedożywienia. Przy przyjęciu oceniono ryzyko upadku według skali Tinetti. Liczba punktów wynosiła 13, co oznaczało zwiększone ryzyko upadku.

Kobieta aktualnie jest w pierwszej dobie pobytu w oddziale psychiatrycznym. Kontakt $\mathrm{z}$ pacjentką prawidłowy. Od miesiąca pogarsza się stan zdrowotny pacjentki. Schudła 10kg w ciągu 2 miesięcy. Niechętnie opuszcza łóżko i zaniedbuje czynności higieniczne. W wywiadzie chora zgłasza lęk przed wzrostem masy ciała. Nie chce patrzeć na swoje ciało w lustrze. Odwodnienie spowodowane jest zażywaniem środków przeczyszczających od kilku tygodni. Na chwilę obecną ryzyko upadku według skali Tinetti wynosi 12. Ciśnienie tętnicze wynosi $100 / 60 \mathrm{mmHg}$. Temperatura ciała w normie $-36,4{ }^{\circ} \mathrm{C}$. Chora wykazuje deficyt wiedzy na temat choroby i samoopieki. 
W Tabeli 1. zaprezentowano szczegółowe informacje o chorej oraz wyniki badania podmiotowego.

\begin{tabular}{|l|l|}
\hline Dane socjodemograficzne \\
\hline Rok urodzenia: 02.01.2000r. & Płeć: Kobieta \\
\hline Stan cywilny: Panna & Wykonywany zawód: Fryzjerka \\
\hline
\end{tabular}

Tabela 1. Arkusz indywidualnego opisu przypadku opracowanie na podstawie Lesińska-Sawicka M (2009).

\begin{tabular}{|l|}
\hline \multicolumn{1}{|c|}{ STAN OGÓLNY (podczas zbierania wywiadu) } \\
\hline Temperatura: $36,4{ }^{\circ} \mathrm{C}$ \\
\hline Tętno:(liczba / napięcie / rytm) 74/min, dobrze napięte, miarowe \\
\hline Oddechy: 16 odd./min. \\
\hline Ciśnienie tętnicze: $100 / 60 \mathrm{mmHg}$ \\
\hline Masa ciała: $44 \mathrm{~kg}$ \\
\hline Wzrost: $159 \mathrm{~cm}$ \\
\hline BMI: 17,4 - niedowaga \\
\hline
\end{tabular}

\begin{tabular}{|l|}
\hline \multicolumn{1}{|c|}{ WYWIAD RODZINNY } \\
\hline Członkowie rodziny: Mama (45lat), tata [46lat) \\
Ważne wydarzenia w rodzinie - ostatnie lata: brak danych \\
Choroby występujące w rodzinie: Alzheimer, nadciśnienie tętnicze krwi \\
Hobby/zainteresowania: czytanie książek \\
Formy spędzania czasu wolnego: oglądanie filmów \\
Nałogi w rodzinie: palenie tytoniu \\
Błędy żywieniowe - jakościowe i ilościowe: spożywanie produktów z \\
duża zawartościq soli \\
Ograniczenia/przeciążenia psychicznego/fizyczne: anoreksja \\
Ograniczone kontakty/brak wsparcia społecznego: brak danych \\
\hline
\end{tabular}


Tabela 2. Badanie fizykalne - opracowanie na podstawie Lesińska--Sawicka M (2009).

\begin{tabular}{|c|c|c|c|c|c|c|}
\hline \multicolumn{2}{|c|}{ SKÓRA } \\
\hline $\begin{array}{c}\text { napięci } \\
\text { e }\end{array}$ & $\begin{array}{c}\text { tempera } \\
\text { tura }\end{array}$ & zabarwienie & $\begin{array}{c}\text { wilgot } \\
\text { ność }\end{array}$ & $\begin{array}{c}\text { stan } \\
\text { higieni } \\
\text { czny }\end{array}$ & $\begin{array}{c}\text { inne } \\
\text { obja } \\
\text { wy }\end{array}$ & $\begin{array}{c}\text { stan rany } \\
\text { pooperac } \\
\text { yjnej }\end{array}$ \\
\hline $\begin{array}{c}\text { prawidł } \\
\text { owe }\end{array}$ & $36,4^{\circ} \mathrm{C}$ & $\begin{array}{c}\text { nieprawidłow } \\
\text { e/skóra blada }\end{array}$ & $\begin{array}{c}\text { Skóra } \\
\text { sucha }\end{array}$ & średni & brak & $\begin{array}{c}\text { nie } \\
\text { dotyczy }\end{array}$ \\
\hline
\end{tabular}

\begin{tabular}{|c|c|c|c|c|}
\hline \multicolumn{5}{|c|}{ UKŁAD ODDECHOWY } \\
\hline $\begin{array}{c}\text { liczba } \\
\text { oddechów }\end{array}$ & typ oddechu & kaszel & inne objawy & $\begin{array}{c}\text { wyroby } \\
\text { medyczne }\end{array}$ \\
\hline $16 /$ min & prawidłowy & brak & brak & nie dotyczy \\
\hline
\end{tabular}

\begin{tabular}{|c|c|c|c|c|c|c|}
\hline \multicolumn{7}{|c|}{ UKŁAD KRĄŻĖNI } \\
\hline ciśnienie & tętno & sinica & obrzęki & duszność & $\begin{array}{c}\text { inne } \\
\text { objawy }\end{array}$ & saturacja \\
\hline $\begin{array}{c}100 / 60 \\
\mathrm{mmHg}\end{array}$ & $74 / \mathrm{min}$ & brak & brak & brak & brak & $\begin{array}{c}98 \% \\
\mathrm{~s} \% 2\end{array}$ \\
\hline
\end{tabular}

\begin{tabular}{|c|c|c|c|c|c|}
\hline \multicolumn{7}{|c|}{ UKŁAD POKARMOWY } \\
\hline uzębienie & łaknienie & Stolec & dieta & $\begin{array}{c}\text { inne } \\
\text { objawy }\end{array}$ & $\begin{array}{c}\text { sposób } \\
\text { odżywiania }\end{array}$ \\
\hline $\begin{array}{l}\text { Wszystkie } \\
\text { zęby stałe }\end{array}$ & zaburzone & Biegunki & lekkostrawna & brak & doustnie \\
\hline
\end{tabular}

\begin{tabular}{|c|c|c|c|}
\hline \multicolumn{4}{|c|}{ UKŁAD MOCZOWY } \\
\hline objętość & Jakość & inne objawy & $\begin{array}{c}\text { wyroby } \\
\text { medyczne }\end{array}$ \\
\hline 1,01 & Słomkowy & brak & nie dotyczy \\
\hline
\end{tabular}




\begin{tabular}{|c|c|c|}
\hline \multicolumn{3}{|c|}{ UKŁAD PŁCIOWY } \\
\hline cykl płciowy & inne objawy & inne cechy (u dzieci) \\
\hline prawidłowy & brak & nie dotyczy \\
\hline
\end{tabular}

\begin{tabular}{|c|c|c|c|}
\hline \multicolumn{4}{|c|}{ UKŁAD NERWOWY } \\
\hline $\begin{array}{c}\text { świadomość } \\
\text { wg skali Glasgow }\end{array}$ & $\begin{array}{c}\text { niedowłady / } \\
\text { drżenia }\end{array}$ & mowa & inne objawy \\
\hline 15 & brak & brak zaburzeń & brak \\
\hline
\end{tabular}

\section{Stan psychiczny i społeczny podopiecznego}

\begin{tabular}{|c|c|c|c|}
\hline sen & nastrój & inne objawy & $\begin{array}{c}\text { ocena wg skali } \\
\text { GDS (seniorzy) }\end{array}$ \\
\hline \multirow{3}{*}{ prawidłowy } & \multirow{2}{*}{ obniżony } & niepokój przed & \\
& & wzrostem wagi & \\
& & ciała, niechęć do & \\
& & dbałości o higienę & nie dotyczy \\
& & osobistą, & \\
& & stosowanie & \\
& & środków & \\
& & przeczyszczających & \\
\hline
\end{tabular}

\section{Diagnozy i interwencje pielęgniarskie}

Po przeprowadzonym badaniu podmiotowym i przedmiotowym wyróżnia się następujące problemy: osłabienie na skutek nieprawidłowej wagi ciała, odwodnienie organizmu spowodowane stosowaniem środków przeczyszczających, częste zawroty głowy prowadzące do upadku, lęk przed wzrostem wagi ciała, zaniedbywanie czynności higienicznych, brak wiedzy na temat choroby i samoopieki. 
Poniżej przedstawiono plan opieki pielęgniarskiej nad pacjentką $\mathrm{w}$ odniesieniu do zdiagnozowanych problemów pielęgnacyjnych z wykorzystaniem Międzynarodowej Klasyfikacji Praktyki Pielęgniarskiej ICNP® (Tabela 3.)

Opieka została zaplanowana i zrealizowana w oparciu o modele D. Orem częściowo-kompensacyjny i wspierająco-edukacyjny oraz B. Neuman.

Poniżej, w Tabeli 3., zaprezentowano najważniejsze problemy pielęgnacyjne opisywanego chorego $\mathrm{w}$ sposób tradycyjny oraz z wykorzystaniem ICNPß.

Tabela 3. Proces pielęgnowania pacjentki $\mathrm{z}$ anoreksją z wykorzystaniem ICNP®.

\begin{tabular}{|c|c|}
\hline Problem pielęgnacyjny I & Diagnoza negatywna (+kod ICNP®) \\
\hline $\begin{array}{l}\text { Osłabienie pacjentki } \\
\text { spowodowane niedowagą }\end{array}$ & Osłabienie [10022880] \\
\hline $\begin{array}{l}\text { Cel planowanych działań } \\
\text { pielęgniarskich: }\end{array}$ & $\begin{array}{l}\text { Przywrócenie prawidłowej masy } \\
\text { ciała }\end{array}$ \\
\hline $\begin{array}{l}\text { Planowane interwencje } \\
\text { pielęgniarskie: }\end{array}$ & Interwencje pielęgniarskie ICNP®: \\
\hline $\begin{array}{l}\text { - codzienna kontrola masy } \\
\text { ciała; } \\
\text { - kontrola przyjmowanych } \\
\text { posiłków; } \\
\text { - regularne przyjmowanie } \\
\text { posiłków; } \\
\text { - zastosowanie diety } \\
\text { wysokokalorycznej; } \\
\text { - rozmowa z dietetykiem; }\end{array}$ & $\begin{array}{l}\text { - monitorowanie wagi ciała } \\
\text { [10032121] } \\
\text { - termin z osi D: kontrolowanie } \\
\text { [10005142] + termin z osi Ś: } \\
\text { posiłek [10011809] } \\
\text { - doskonalenie reżimu diety } \\
\text { [10036447] } \\
\text { - zapewnienie wsparcia } \\
\text { społecznego [10027046] }\end{array}$ \\
\hline $\begin{array}{l}\text { Ocena realizowanych działań } \\
\text { pielęgniarskich: Zwiększono }\end{array}$ & $\begin{array}{l}\text { Diagnoza pozytywna/negatywna } \\
\text { ICNP®: }\end{array}$ \\
\hline
\end{tabular}




\begin{tabular}{|c|c|}
\hline masę ciała & $\begin{array}{l}\text { Poprawa statusu odżywienia } \\
{[10035569]}\end{array}$ \\
\hline \multicolumn{2}{|c|}{ Uzasadnienie planowanej interwencji pielęgniarskiej: } \\
\hline \multicolumn{2}{|c|}{$\begin{array}{l}\text { Osłabienie powoduje ograniczenie do wykonywania codziennych } \\
\text { aktywności. Interwencje pozwolą osiągnąć odpowiednią masę ciała } \\
\text { do prawidłowego funkcjonowania organizmu }[5,6] \text {. }\end{array}$} \\
\hline Problem pielęgnacyjny II & Diagnoza negatywna (+kod ICNP®) \\
\hline $\begin{array}{l}\text { Odwodnienie organizmu } \mathrm{z} \\
\text { powodu stosowania środków } \\
\text { przeczyszczających }\end{array}$ & Odwodnienie [10041882] \\
\hline $\begin{array}{l}\text { Cel planowanych działań } \\
\text { pielęgniarskich: }\end{array}$ & $\begin{array}{l}\text { Przywrócenie } \quad \text { prawidłowej } \\
\text { gospodarki wodno-elektrolitowej }\end{array}$ \\
\hline $\begin{array}{l}\text { Planowane interwencje } \\
\text { pielęgniarskie: }\end{array}$ & Interwencje pielęgniarskie ICNP®: \\
\hline $\begin{array}{l}\text { - ocena stanu nawodnienia } \\
\text { (diureza, stan skóry i błon } \\
\text { śluzowych, pomiar masy } \\
\text { ciała); } \\
\text { - prowadzenie bilansu wodno- } \\
\text { elektrolitowego; } \\
\text { - zachęcenie pacjentki do picia } \\
\text { 1,5-2 l wody dziennie; } \\
\text { - ocena stanu ogólnego } \\
\text { pacjentki (temperatura, RR, } \\
\text { tętno, ilość oddechów); } \\
\text { - rozmowa z psychologiem; } \\
\text { - wytłumaczenie } \\
\text { konsekwencji stosowania } \\
\text { środków przeczyszczających; } \\
\text { - utrzymanie mikroklimatu } \\
\text { (60\% wilgotności } 19^{\circ} \mathrm{C} \text { ); }\end{array}$ & $\begin{array}{l}\text { - ocenianie równowagi płynów } \\
\text { [10037881] } \\
\text { - monitorowanie przyjmowania } \\
\text { płynów [10035303] } \\
\text { - monitorowanie wydalanych } \\
\text { płynów [10035319] } \\
\text { - zarządzanie } \\
\text { nawodnieniem[10046317] } \\
\text { - monitorowanie statusu } \\
\text { fizjologicznego [10012183] } \\
\text { - monitorowanie wagi ciała } \\
\text { [10032121] } \\
\text { - zapewnienie wsparcia } \\
\text { emocjonalnego [10027051] } \\
\text { - promowanie zachowań } \\
\text { prozdrowotnych [10032465] } \\
\text { - zarządzanie bezpieczeństwem }\end{array}$ \\
\hline
\end{tabular}




\begin{tabular}{|c|c|}
\hline & $\begin{array}{l}\text { środowiska [10042507] + } \\
\text { powietrze [10002061] }\end{array}$ \\
\hline $\begin{array}{l}\text { Ocena realizowanych działań } \\
\text { pielęgniarskich: Gospodarka } \\
\text { wodno-elektrolitowa w } \\
\text { normie. }\end{array}$ & $\begin{array}{ll}\text { Diagnoza } & \text { pozytywna/negatywna } \\
\text { ICNP@: } & \\
\text { Efektywna } & \text { równowaga } \\
\text { elektrolitowa [10033709] }\end{array}$ \\
\hline \multicolumn{2}{|c|}{ Uzasadnienie planowanej interwencji pielęgniarskiej: } \\
\hline \multicolumn{2}{|c|}{$\begin{array}{l}\text { Odwodnienie izotoniczne na skutek stosowania środków } \\
\text { przeczyszczających oznacza zmniejszenie ilości wody i sodu w } \\
\text { organizmie. Kontrola zaburzeń wodno-elektrolitowych pozwoli na } \\
\text { zastosowanie odpowiedniego postępowania i jego oceny. Częste } \\
\text { nawadnianie drogą doustną uzupełni utracone płyny [5]. }\end{array}$} \\
\hline Problem pielęgnacyjny III & Diagnoza negatywna (+kod ICNP®) \\
\hline $\begin{array}{l}\text { Ryzyko upadku spowodowane } \\
\text { zawrotami głowy }\end{array}$ & Ryzyko upadku [10015122] \\
\hline $\begin{array}{l}\text { Cel planowanych działań } \\
\text { pielęgniarskich: }\end{array}$ & Wyeliminowanie ryzyka upadku \\
\hline $\begin{array}{l}\text { Planowane interwencje } \\
\text { pielęgniarskie: }\end{array}$ & Interwencje pielęgniarskie ICNP®: \\
\hline $\begin{array}{l}\text { - towarzyszenie chorej przy } \\
\text { dłuższych spacerach; } \\
\text { - stosowanie podkładów } \\
\text { antypoślizgowych, } \\
\text { dodatkowych uchwytów; } \\
\text { - zadbanie o to, by pacjentka } \\
\text { nie nosiła luźnego obuwia; } \\
\text { - zachęcenie pacjentki do } \\
\text { korzystania z kul, wózka; } \\
\text { - nauka pacjentki i rodziny w } \\
\text { ramach postępowania przy } \\
\text { zawrotach głowy; }\end{array}$ & $\begin{array}{l}\text { - używanie (wykorzystywanie) } \\
\text { wsparcia do pozycjonowania } \\
\text { [10035467] } \\
\text { - promowanie przestrzegania } \\
\text { reżimu [10032449] } \\
\text { - promowanie efektywnego } \\
\text { radzenia sobie [10035936] } \\
\text { - promowanie chodzenia z } \\
\text { wykorzystaniem urządzenia } \\
\text { [10037636] } \\
\text { - nauczanie o chorobie [10024116] } \\
\text { - nauczanie rodziny o chorobie }\end{array}$ \\
\hline
\end{tabular}




\begin{tabular}{|c|c|}
\hline & [10021719] \\
\hline $\begin{array}{l}\text { Ocena realizowanych działań } \\
\text { pielęgniarskich: Nie doszło do } \\
\text { upadku }\end{array}$ & $\begin{array}{l}\text { Diagnoza pozytywna/negatywna } \\
\text { ICNP®: } \\
\text { Bez upadku [10034704] }\end{array}$ \\
\hline \multicolumn{2}{|c|}{ Uzasadnienie planowanej interwencji pielęgniarskiej: } \\
\hline $\begin{array}{l}\text { Stosowanie udogodnień zmnie } \\
\text { i pacjentki na temat postę } \\
\text { zachować bezpieczeństwo. } \\
\text { występowaniu powikłań }[5,6] \text {. }\end{array}$ & $\begin{array}{l}\text { Szy ryzyko upadku. Edukacja rodziny } \\
\text { powania podczas upadku pozwoli } \\
\text { Podjęte działania zapobiegają }\end{array}$ \\
\hline Problem pielęgnacyjny IV & Diagnoza negatywna (+kod ICNP®) \\
\hline $\begin{array}{lll}\text { Niepokój } & \text { przed } & \text { wzrostem } \\
\text { wagi ciała } & & \\
\end{array}$ & Niepokój [10000477] \\
\hline $\begin{array}{l}\text { Cel planowanych działań } \\
\text { pielęgniarskich: }\end{array}$ & Wyeliminowanie niepokoju \\
\hline $\begin{array}{l}\text { Planowane interwencje } \\
\text { pielęgniarskie: }\end{array}$ & Interwencje pielęgniarskie ICNP®: \\
\hline $\begin{array}{l}\text { - ocena stanu ogólnego } \\
\text { pacjenta ( RR, tętno, } \\
\text { temperatura, saturacja, liczba } \\
\text { oddechów); } \\
\text { - podaż leków uspokajających } \\
\text { na pisemne zlecenie lekarskie; } \\
\text { - przekonanie do rozmów z } \\
\text { psychologiem; } \\
\text { - zapewnienie odpowiednich } \\
\text { warunków na spożycie } \\
\text { posiłku, np. przewietrzenie } \\
\text { sali; } \\
\text { - zapewnienie choremu } \\
\text { odpowiedniego komfortu oraz } \\
\text { bezpieczeństwa poprzez: miłą }\end{array}$ & $\begin{array}{l}\text { - monitorowanie statusu } \\
\text { fizjologicznego [10012183] } \\
\text { - administrowanie lekiem } \\
\text { [10025444] } \\
\text { - zapewnienie wsparcia } \\
\text { emocjonalnego [10027051] } \\
\text { - zarządzanie bezpieczeństwem } \\
\text { środowiska [10042507] } \\
\text { - Zarządzanie nastrojem } \\
\text { [10036256] } \\
\text { - zachowanie interaktywne } \\
\text { [10010463] } \\
\text { - promowanie wsparcia rodziny } \\
\text { [10036078] }\end{array}$ \\
\hline
\end{tabular}




\begin{tabular}{|l|l|}
\hline $\begin{array}{l}\text { atmosferę, życzliwe rozmowy; } \\
\text { - okazanie zrozumienia; } \\
\text { - aktywne słuchanie; }\end{array}$ \\
- zapewnienie obecności \\
rodziny przy pacjencie;
\end{tabular}




\begin{tabular}{|c|c|}
\hline $\begin{array}{l}\text { czesanie, usuwanie resztek } \\
\text { jedzenia, mycie zębów); } \\
\text { - zapewnienie warunków } \\
\text { intymności w trakcie toalety; } \\
\text { - dostrzeganie wysiłków } \\
\text { pacjenta i stosowanie pochwał } \\
\text { słownych }\end{array}$ & \\
\hline $\begin{array}{l}\text { Ocena realizowanych działań } \\
\text { pielęgniarskich: Pacjentka } \\
\text { chętniej dbała o swój wygląd }\end{array}$ & $\begin{array}{l}\text { Diagnoza pozytywna/negatywna } \\
\text { ICNP®: } \\
\text { zdolny/a do wykonywania higieny } \\
{[10028708]}\end{array}$ \\
\hline \multicolumn{2}{|c|}{ Uzasadnienie planowanej interwencji pielęgniarskiej: } \\
\hline \multicolumn{2}{|c|}{$\begin{array}{l}\text { Zachowanie czystości skóry poprawia komfort życia i potrzebne jest } \\
\text { do zwiększenia poczucia własnej wartości. Działania mają na celu } \\
\text { zachęcenie pacjentki do większej aktywności w czynnościach } \\
\text { samopielęgnacyjnych. Wdrożenie pacjentki do planu opieki zwiększy } \\
\text { zaangażowanie do dbania o higienę ciała [5]. }\end{array}$} \\
\hline Problem pielęgnacyjny VI & Diagnoza negatywna (+kod ICNP®) \\
\hline $\begin{array}{l}\text { Deficyt wiedzy na temat } \\
\text { choroby i samoopieki }\end{array}$ & $\begin{array}{lll}\text { Brak wiedzy } & \text { o } & \text { chorobie } \\
{[10021994]} & & \\
\end{array}$ \\
\hline $\begin{array}{l}\text { Cel planowanych działań } \\
\text { pielęgniarskich: }\end{array}$ & Uzupełnienie deficytu wiedzy \\
\hline $\begin{array}{l}\text { Planowane interwencje } \\
\text { pielęgniarskie: }\end{array}$ & Interwencje pielęgniarskie ICNP®: \\
\hline $\begin{array}{l}\text { - ocena zdolności } \\
\text { samoopiekuńczych i wiedzy } \\
\text { na temat choroby za pomocą } \\
\text { kwestionariusza EASY-Care; } \\
\text { - udzielanie chorej informacji } \\
\text { dotyczących występujących } \\
\text { dolegliwości oraz }\end{array}$ & $\begin{array}{l}\text { - Ocenianie samoopieki } \\
\text { [10021844] } \\
\text { - Ocenianie wiedzy [10033882] } \\
\text { - Nauczanie o chorobie [10024116] } \\
\text { - Promowanie samoopieki } \\
\text { [10026347] } \\
\text { - Nauczanie o samoopiece }\end{array}$ \\
\hline
\end{tabular}




\begin{tabular}{|l|l|}
\hline sposobów ich zmniejszania; & {$[10045014]$} \\
- podanie broszur, książek, & - Wzmacnianie pozytywnych \\
ulotek, stron internetowych; & zachowań [10036176] \\
- edukacja w zakresie & - Nauczanie rodziny o chorobie \\
przyczyn, objawów i & {$[10021719]$} \\
następstw anoreksji; & \\
- przedstawienie pacjentce \\
propozycji zmiany stylu życia: \\
regularne posiłki, \\
zrównoważona dieta, \\
umiejętne radzenie sobie z \\
problemami; \\
- edukacja rodziny o \\
konieczności pomocy w \\
czynnościach, które sprawiają \\
chorej trudnośc;
\end{tabular}

\section{Dyskusja}

Jest wiele przyczyn jadłowstrętu psychicznego. Predysponuje do tego osobowość, biologia oraz kontakty międzyludzkie. Z powodu wysokiego współczynnika zgonów spowodowanych anoreksją po ukończeniu 24 r.ż. należy jak najszybciej podjąć interwencję 
u specjalisty. Błędem podejmowanym przez osoby chore i ich bliskich jest decyzja o leczeniu domowym, najczęściej nie daje ona odpowiednich rezultatów, takich jak przyrost około kilograma na tydzień. Jeśli po okresie miesiąca masa ciała osoby chorej nie wzrosła, a BMI (Body Mass Index) daje wartość poniżej 15, należy bezwzględnie daną osobę hospitalizować. Leczenie anoreksji to długotrwały i powolny proces, osoba chora wymaga holistycznej opieki. Podstawowymi i najważniejszymi etapami leczenia są przede wszystkim: powolny przyrost masy ciała (początkowo spożywana żywność nie powinna przekraczać więcej niż 50 kcal na kilogram masy ciała), leczenie powikłań ogólnoustrojowych, zachęcanie do walki $\mathrm{z}$ chorobą, szeroko rozumiane edukowanie dotyczące odżywiania, poprawa postrzegania swojej osoby, poprawa relacji rodzinnych, jeśli są zaburzone oraz niedopuszczenie do nawrotów choroby. Leczenie farmakologiczne jest dopuszczone w przypadku obecności przejawów depresyjnych lub obsesyjno-kompulsywnych [8].

Pielęgniarka przyjmująca na oddział osobę cierpiącą z powodu anoreksji powinna: bezwzględnie nawiązać kontakt i wzbudzić zaufanie zarówno pacjenta jak i rodziny, zapoznać ich z obowiązującymi zasadami i planem leczenia, przejrzeć rzeczy osobiste pod kątem posiadania leków na przeczyszczenie, zmierzyć podstawowe parametry życiowe oraz zważyć pacjenta w jego bieliźnie osobistej, prowadzić szczegółową dokumentację oraz wspólnie z resztą zespołu terapeutycznego ustalić odpowiednią dietę uwzględniającą stan chorego. Istotne $\mathrm{w}$ leczeniu anoreksji jest angażowanie się rodziny, co wzbudzi u pacjenta większe poczucie bezpieczeństwa. Jadłowstręt psychiczny sprawia wiele trudności całemu personelowi medycznemu, przyczyną tego jest głównie odmowa współpracy i brak motywacji ze strony pacjenta. Z tego powodu każdy chorujący na anoreksję wymaga zapewnienia 
indywidualnej opieki - całkowite wyleczenie jest możliwe, jednakże wymaga ciężkiej pracy z obu stron [9].

\section{Wnioski}

1. Holistyczne podejście do pacjentki ze strony personelu medycznego pozwoliło na poprawę samopoczucia chorej, natomiast w celu osiągnięcia całkowitej równowagi psychicznej i fizycznej pacjentki działania pielęgniarskie powinny być kontynuowane.

2. Poprzez zastosowanie $\mathrm{w}$ procesie pielęgnowania diagnoz i interwencji pielęgniarskich ICNP® możliwe jest zapewnienie pacjentce $\mathrm{z}$ anoreksją udoskonalonej opieki.

3. Zachęcanie do dbania o higienę osobistą pacjentki i pomoc jej w tym zwiększyło u niej poczucie własnej wartości.

4. Poprzez uzupełnienie wiedzy dotyczącej choroby i samoopieki w niej unikniemy niechcianych konsekwencji przebiegu choroby, a co najważniejsze możliwy będzie całkowity powrót do zdrowia.

\section{Bibliografia/Bibliography:}

1. Starzomska M. Anoreksja. Oficyna Wydawnicza IMPULS. Kraków 2006: 13-15.

2. Kotwas A. i wsp. Występowanie zaburzeń odżywiania wśród uczennic szkół ponadgimnazjalnych. Psychiatria Polska nr 127. Szczecin 2017:2.

3. https://www.mp.pl/pacjent/psychiatria/choroby/75618,zaburzeniaodzywiania, dostęp dnia 8.04.2020r.

4. Andruszkiewicz A., Banaszkiewicz M. Promocja zdrowia dla studentów studiów licencjackich kierunku pielęgniarstwo i położnictwo. Tom 2 . Wydawnictwo Lekarskie PZWL. Warszawa 2010:160-161. 
5. Kózka M., Płaszewska-Żywko L. Diagnozy i interwencje pielęgniarskie. Wydawnictwo Lekarskie PZWL. Warszawa 2015:91,118-119,170171,253,264-265.

6. Wieczorowska-Tobis K., Talarska D. Geriatria i pielęgniarstwo geriatryczne. Wydawnictwo Lekarskie PZWL. Warszawa 2017:175,178,313-314.

7. Ciechaniewicz W. Pielęgniarstwo. Ćwiczenia. Podręcznik dla studiów medycznych. TOM 1 i 2. Wydawnictwo Lekarskie PZWL. Warszawa 2010: 888.

8. Pawlaczyk B. Zarys pediatrii. Podręcznik dla studentów pielęgniarstwa. Wydawnictwo Lekarskie PZWL, Warszawa 2005:120-124.

9. Gawlowski K. Udział pielęgniarki w kompleksowym leczeniu jadłowstrętu psychicznego pacjenta hospitalizowanego. Puls Uczelni. Opole 2012;(4):17-21. 